DOI: https://doi.org/10.31933/dijms.v2i3 Received: 21 November 2020, Revised: 25 December 2020, Publish: 21 January 2021

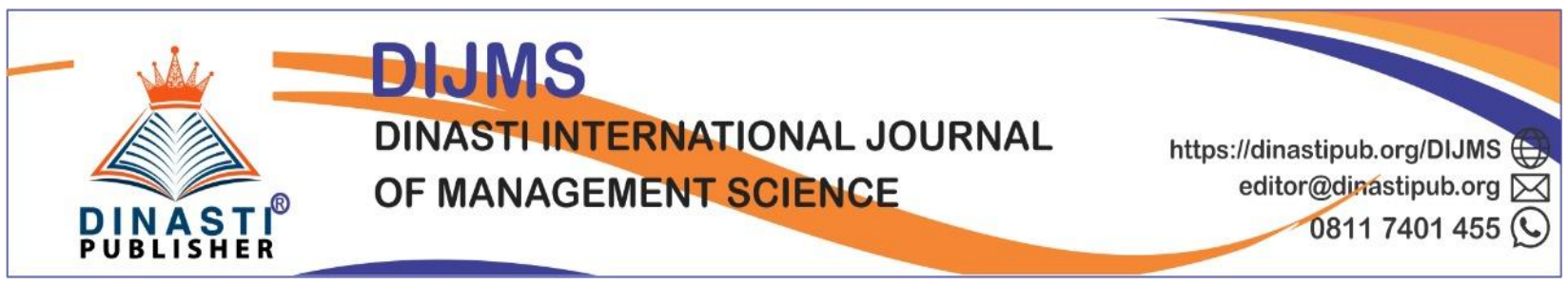

\title{
THE IMPLEMENTATION OF SMART METHOD FOR IMPROVING JOB SATISFACTION
}

\author{
Zakiyya Tunnufus ${ }^{1}$, Sholeh Rosyad ${ }^{2}$, Anoesyirwan Moeins ${ }^{3}$ \\ ${ }^{1)}$ STIE LA TANSA MASHIRO. Indonesia, zakiyyatunnufus@ gmail.com \\ 2) STIE LA TANSA MASHIRO. Indonesia, Kangenceh@gmail.com \\ ${ }^{3)}$ Universitas Persada Indonesia YAI. Jakarta. Indonesia, iwansp3@yahoo.co.id
}

Corresponding Author: First Author

\begin{abstract}
The assessment of performance are subjective can have an impact on decreasing the job satisfaction of employees. when employees feel that they have worked well but based on the results of the assessment of their performance is not considered to provide optimum performance of them will feel disappointed. This study aims to evaluate the performance assessment by using the SMART method in PT. BNI Tbk. Main Branch Tangerang. The method used in this research is descriptive verificative, with a total sample of 98. Leverage data is done using kuesianer distributed to the employees of the bank PT. BNI Tbk. Main Branch Tangerang. The results showed that the performance assessment by using the SMART method can not be applied because some of the indicators SMART can not be implemented, while the job satisfaction provided by Bank BNI to the employee is still not optimal. The test results also indicate that performance assessment has positive and highly significant impact on job satisfaction of employees in the Bank PT. BNI Tbk. Main Branch Tangerang.
\end{abstract}

Keywords : Smart Method, Job Satisfaction

\section{INTRODUCTION}

Every company want to have employees who are airhigh performance, because employees who have high performance will be memberi 's contribution to the pento achievean objectives of the company. Ke is the result of work or anything that can be done which in quality or quantity can be achieved by an employee in carrying out their duties in accordance with the responsibilities assigned to him (Mangkunagara, 2009; Gilbert in Notoatmodjo, 2009). To produce the performance as expected, the employee must have the various elements required to achieve it, such as: competence, achievement, discipline, motivation, responsibility and so on. Element-this element can drive in better performance, therefore unsur these elements need to be controlled in such a way in order to continue to increase.

Nevertheless shave become khodrat that human behavior is difficult to remain in a condition of constant, perihuman behavior is always changing which is influenced by certain circumstances and conditions. Pengendalian of behavior that can encourage or lose 
employees to achieve better performance can be done through a performance appraisal process, i.e. a process in terms of the determination of a shared understanding of what will be achieved, and an approach to managing and developing people to perform a variety of increased. This increase is not can occur only with the sistem which is controlled by the management to manage performance of their employees, but also through an approach into the direction of managing and developing people which allows them to set development and performance of their own within the framework of clear targets and standards that have been approved by the supervisor they (Rivai, 2005).

Performance assessment in general can be used as benchmark companies in making decisions relating to the awarding of bonuses, incentives, mutation of the employee, store and training, promotion, placement, career development even up to the dismissal of an employee, ur the reason is of course the assessment of the performance of the memhas a very important role, by karenaher employee performance appraisal needs to be done with a very open and objective, not bby melakukan assessment is subjective, unilateral and d is notof like or not like.

In assessing the performance of employees of PT BNI rests on indicators of the quality and quantity of work, employee behavior in the work and effectiveness of the working hours, which is considered sufficient to represent to assess the performance of employees. However it seems that the method used by PT BNI does not provide optimal results, still lhear the voices of discontent from the employees against the results of the assessment and occurs volatile performance of irregular shape, as shown by the performance graphs, as presented in figure 1.

See performance results like in figure 1, it is seen that PT BNI Tbk. Still using the method of bell curve (the ranking of the forced bell-shaped), where the HR department put the ratings for example on the basis of achievement, attitude and work behavior, through 5 categories : Very Good/Good/Quite Good/Less Good/Not Good. And the results of the assessment are dominated by the results of the better and quite good for the period 2012 to 2015. The consequences of assessment methods that can only employees who received wage increases only who got the category quite well, good and very good and 2 other categories do not get the increase.

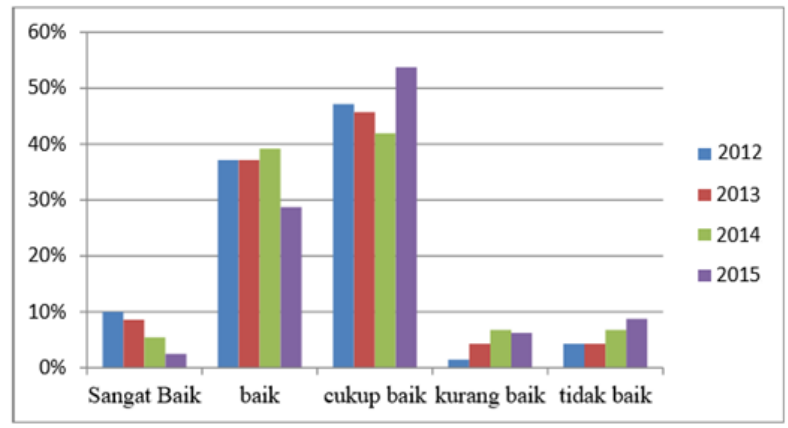

Source: Personnel Data of PT BNI tbk Main Branches Tangerang processed. Figure 1. Performance of employees of PT BNI Tbk. Main branch Tangerang period 2016-2019

It may just be a method of assessment of kinf PT. BNI is right, if his judgment is based on objectivity, but if it still contained elements of subjectivity then it probably will have an impact on the dissatisfaction of the employees who acquire the assessment work is not good and very not. To determine the condition of job satisfaction of employees with 
regard to the results of the assessment, has done a pre survey about the satisfaction of employees to 15 employees PT PT. BNI Tbk. The Main branch of Tangerang, and the result is nampr performance appraisal conducted by PT BNI is still yet to be fully accepted by the employees. This is shown by the still large enough percentage of employees still feel less satisfied, as indicated by table 1 below:

Table 1 Job Satisfaction

\begin{tabular}{|l|l|c|}
\hline No & \multicolumn{1}{|c|}{ Statement of } & $\begin{array}{c}\text { the } \\
\text { Percentage } \\
\text { of }\end{array}$ \\
\hline 1 & Company always gives awards to outstanding employees & $77 \%$ \\
\hline 2 & Chance of promotion given openly for employees & $70 \%$ \\
\hline 3 & Allowances ingive appropriate expertise of employees & $80 \%$ \\
\hline 4 & Penilaian performance is made objectively & $66 \%$ \\
\hline 5 & the Results of the penilaian performance You already have expectations & $65 \%$ \\
\hline
\end{tabular}

\section{Source: Results of pre-survey processed}

From tabel above can be seen that there are still employees of PT PT. BNI Tbk. The Main branch of Tangerang who still have topuasan work less. sch as well as promotion opportunities are assessed by the majority of them did not open, and they felt that promotion opportunities are not based on the results of the performance assessment. The mereka judged that the performance evaluation is done is not done objectively and the results of the performance assessment is not in accordance with their expectations. They feel that they already contribute with the gained outcomes already targeted but the results of the assessment of the performance of the same with less contribute.

Based on the symptoms of the problem above may preferably PT BNI replace or search methods performance appraisal a new one that can minimize the discontent of their employees. Some of the consultants and experts of HUMAN resources continues to strive to find appropriate methods to assess the performance of employees, and one of them is the SMART method that is based on the target or target work. SMART is an abbreviation of Specipic, Measurable, Accurate, Realistic And Time Bound. This method to set or describe the target clearly and without ambiguous (specific), using the measurement of concrete such as how many or when a target can be known has been achieved (measurable), stressed on the importance of how realistic a target (realistic), there is conformity to superiors, management and the company as a whole (accurate) and there is a time measure with a time frame in starting and deadlines are expected to be able to complete the objectives that have been set. This calculation can be described with a sorting strategy into short term tactics or daily activity, then the tactics of the medium-term, and long-term or annual and five-year (time bound).

\section{LITERATURE REVIEW Performance Assessment}

Performance assessment is a key factor in developing the potential of employees to effectively and efficiently due to the presence of the policy or a better program for human resources in an organization. Individual performance assessment is very beneficial for the growth of the organization as a whole. Bernardin and Russel in the Khaerul Umam (2010), 
suggests that performance Assessment is how to measure the contributions of individuals (employees) on organisasi their place of work. While the mccording to Sedarmayanti (2011), performance Appraisal is a formal system to inspect/assess and evaluate bperiodically the performance of someone.

From the above description it can be concluded that the assessment of the performance ofja employees how to measure the contributions of individuals (employees) in the organization where they work with a formal system to check/review and evaluate periodically the performance of someone. Penilaian performance is categorized as one that is evaluation and development. Ss sesd are evaluation results of the assessment should be used as: a) the base compensation, b) staffing decision and c) a basis to evaluate the selection system. Meanwhile, as something that is development.ent Assessors must complete: a) the Achievements of the real, which achieved the individual; b) the Weaknesses of the individual that hinder performance and c) develop prestasi-achievements (Umam; 2010). Meanwhile Sedarmayanti (2011) explains that the purpose of performance appraisal is:

1) Improve employee performance with how to help them realize and use their potential to the full in realizing the goals of the organization.

2) Provide information to employees and leadership as a basis for taking decisions relating to the work.

\section{The method of SMART}

A lot of the management in the company that determine the target individual employees based on numbers and criteria that are measurable. And the more detail, using the SMART method. SMART means it has a purpose yesng specific and measurable (Specific and Measurable), achievable/realistic (Attainable), relevant and timed (Relevant and Timely). Goals that are formulated in a SMART method as the targets are measured automatically will be more motivating than a goal that is not clear.

Paul J. Meyer describes the characteristics of the measurement SMART as follows;

1) Specific means to describe the target clearly and without ambiguous. Some of the attributes that is used is to evaluate: what is to be achieved? Reason or advantage to be achieved by reaching the targets? Anyone who is related and associated with the achievement of the target? Where the location or facility/infrastructure what is needed to achieve the goal?

2) Measured, i.e. the measurement of concrete such as how many or when a target can be known has been achieved. These things must be taken into account from the beginning of the determination of the target.

3) Realistic (attainable), that emphasize on the importance of how realistic a target that. If the target is too far outside the standard, can be demotivators because it does not fit with the expertise, capacity, ability, and behaviors held to achieve these goals. So the possibility of how a goal can be achieved can be answered when beginning to assess a feasibility of the target.

4) Relevant, sa goal could be specific, measurable, realistic, and there is a time limit, but if it is not relevant to superiors, management and the company as a whole then it will not be fully supported by a work team or a colleague/work partner other.

5) Timely, measure of time with the time frame in starting and deadlines are expected to be able to complete the objectives that have been set. This calculation can be described with a sorting strategy into short term tactics or daily activity, then the tactics of the medium- 
term, and long-term or annual and five-yearly so that the indicators indicate progress towards achievement cant be evaluated and re-evaluation.

\section{The satisfaction of Employee}

Citing the opinion of Locke, Luthans (2005) argues that job satisfaction is a positive emotional state of a person arising from the appreciation for the work that has been done. Kepuasan work this is an achievement which achieved a person which is compared with how well his job provides something useful for him. Defincontents of a more comprehensive covering of the reaction or the cognitive, affective, and evaluative and states that job satisfaction is "the emotional state of happy or positive emotions that come from the assessment work or work experience person." Job satisfaction is the result of the perception of employees regarding how well their job provides things that are rated important. There are three dimensions that are generally accepted in job satisfaction.

1) Kepuasan work is an emotional response to the work situation. Thus, job satisfaction can be seen and may be suspected.

2) job satisfaction is often determined according to how well the results achieved meet or exceed expectations.

3) job satisfaction represents some of the attitudes relating.

According to the Malthis (2006) job satisfaction thereis a positive emotional state from evaluating one's work experience. Job dissatisfaction arises when these expectations are not met. While Robbins (2010) defines job satisfaction as a general attitude towards one's job, the difference between the number of rewards received by a worker and the amount they believe they should receive.

Job satisfaction has many dimensions, in general, is the satisfaction in the work itself, the salary, the recognition, the relationship between the supervisor with the workforce, and the opportunity to advance. Each dimension produces a feeling of satisfied overall with the work itself. Measure the absolute level of satisfaction does not exist, because every individual employee is different standards of satisfaction. Indicators of job satisfaction can be measured by the discipline, morale, and labour turnover is small, then the relative employee satisfaction is good but on the contrary, if the discipline, morale and labour turnover is large, maka job satisfaction of employees in a company rated less.

\section{Framework}

To be denied that the performance of the employee is not able applicable constant, meaning that at one time their performance will drop or rise, because it is influenced by various behavioral factors such as demotivation, stress, satisfaction of work, placement not appropriate, feeling unfairly treated and so on. Therefore to be able to continue to monitor the performance of the industry need to do evaluation or assessment of the performance of a time-ly. The assessment process is correlated effectively with the level of satisfaction and engagement of employees is high (Dechev, 2010), performance appraisal system is not effective will create chaos and confusion from top to bottom as a result chances of success and the growth of the organization going down (Khan, 2008), assessment of employees to encourage performance monitoring without the consequences of monetary, have a detrimental effect on the level of job satisfaction (Kampköttert, 2014).

Penilaian performance can help enhance employee performance by helping them realize and use their potential to the full in realizing the goals of the organization. Can 
provide information to employees and leadership as a basis for taking decisions relating to the work. The performance assessment is beneficial for organizations to perform adjustment of the compensation; performance improvement; plan kent practice and development; decisionmaking for placement, promotion, transfer, dismissal, dismissal, and workforce planning; research employee and melp analysis against design error employees.

The method of SMART in-claim can help management in determining the target individual employees based on numbers and criteria that are measurable. Mmethod SMART, have goals that are specific and measurable (Specific and Measurable), achievable/realistic (Attainable), relevant and timed (Relevant and Timely). Goals that are formulated in a SMART method as the target-measurable targets will automatically motivate more employees. this method seems very objective so as to minimize the dissatisfaction of work of the employee over the results of the assessment work that is subjective.

Based on the above explanation, the paradigm in this study is presented in figure 2.1. the following:

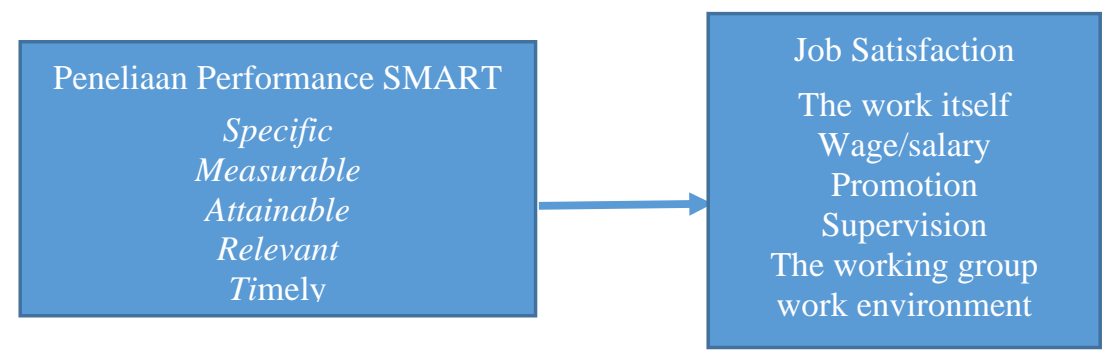

Figure 2 Research Paradigm

\section{RESEARCH METHODS}

This type of research is descriptive verification method because this study aims to explore and analyze the variables of Performance Assessment on the Bank BNI Main Branch Tangerang. The Data required in this research consist of primary data and secondary data. The secondary Data obtained from company documents and the books of literature as well as browsing the internet that provide information about the assessment and satisfaction of employees. While the primary data obtained through observation or direct observation of the company, either through observation, questionnaires and direct interviews with subjects and / or respondents of the study.

The subjects of this research are the employees of the bank, with the unit of analysis all parts in PT BNI Tbk Main Branches of Tangerang with a total population of 931 people. With a population of 931, pengambilan sampel used the technique of sampling by using the Slovin formula, namely:

$$
\mathrm{n}=\mathrm{N} /\left(1+\mathrm{N}(\mathrm{e})^{2}\right. \text {. }
$$

Of the techniques available.but with the degree of trust of $90 \%$, the obtained minimum number of samples as $n=931 /\left(1+931(10 \%)^{2}\right)$ or $n=90,30$.

To explain the question items of the variable system performance assessment, and job satisfaction have been answered by the respondents, further identification of the characteristics of the respondents such as age, gender, education and working period. While for analisis verifikatif muse the method of PLS (partial least Quare), The steps that are used on the model of the PLS is described as follows: 
1) Designing structural model (inner model) model Development based on the concepts and theories to analyze the relationship between the exogenous variables (Performance Appraisal System) and endogenous variable (Job Satisfaction) based on the formulation of the problem.

2) Designing the measurement model (outer model) to determine the nature of the indicators of each variable of the performance appraisal system, and job satisfaction and determine whether the indicator is a reflection or indicator of the formative based on the operational definition of the variable.

3) Diagram Line, can be seen on the image as follows:

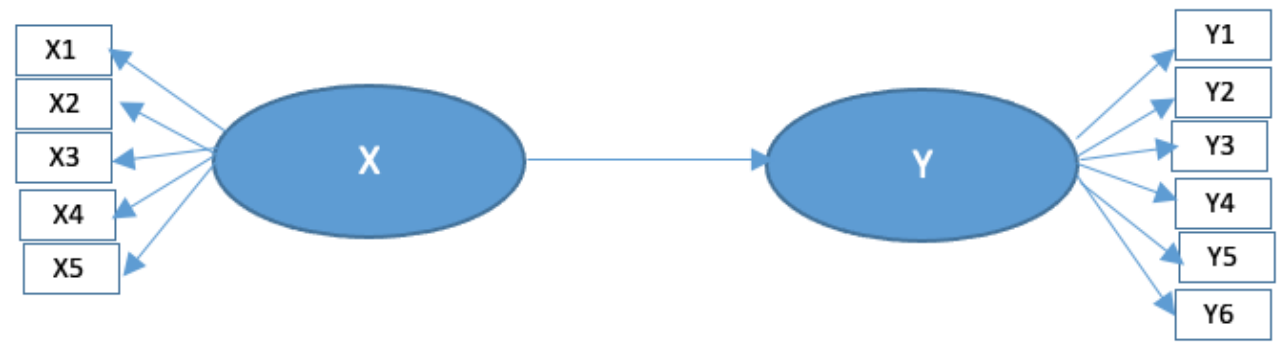

Figure 3. Flow Diagram (Path Diagram) or the Outer Model

4) Goodness of Fit of the Outer Model (measurement model)

a) Convergent Validity the Correlation between the scores of the indicators of reflection and score of the latent variable, using a loading factor of 0.5 to 0.6 was used in the early stages of development.

b) The Discriminant Validity of Measuring indicators of reflection based on the cross loading to the latent variable. Then compare the value of the square rool of average variance extracted (AVE) in each construct correlate with the construct of the model, the value of pengukuranya should be greater than 0.50 .

c) Composite Reliability Indicator block that measures consistent internal of the indicators that form the construct, indicating the degrees that identify the common latent (unobserved) reliability composite has a value of 0.7 .5 ) .

5) Hypothesis Testing

Hypothesis testing using the $t$ test. Testing is done by $\mathrm{t}$-test on the inner model obtained $\mathrm{p}$ value of 0.005 (alpha 5\%), such testing means that there are significant influence variables latent variables performance appraisal system of latent variables to other variables job satisfaction and job stress variables.

\section{FINDINGS AND DISCUSSION}

Analysis descriptive

\section{Assessment of the Performance of SMART on the Employees of the Bank of the BJP Central}

Analysis for variable employee Performance Appraisal using the method of SMART on the Bank of the BJP the Center starting from the dimension "Specific". The results of the calculation of the score from the data obtained from the questionnaire shows that the average value for the dimension it is Currently. However, there are 2 indicators belonging to the lower category, namely: the work to be achieved and involved in the work. This means that the objectives of the work the employees of the bank PT. BNI Tbk. Main branch Tangerang at least already spelled out pretty specific. But there are still many employees who feel that the objectives of the work to be achieved is still not described specifically, but the reason or 
benefit that would be obtained if the target is reached according to their specific, just that the involvement of employees in achieving those goals still agak ambiguous. Temporary facilities and / or infrastructure required to reach the target is already specific enough.

Subsequent analysis conducted on the dimensions of the "Measurable", the Results of the calculation of the score from the data obtained from the questionnaire shows that the average value for this dimension tergolong in the medium category. This shows that the target of the job done already quite scalable. But the indicator of the number of targets that will be achieved is still relatively low meaning that the number of targets that will be achieved is not yet so clear how-berapanya. However time the achievement target is quite measurable where each target should be achieved in a short time. Meanwhile, the distance between one target to the other target also belongs to the category low, it is due to lack of measurability of the amount of the target set.

Subsequent analysis conducted on the dimensions of the "Attainable". The results of the calculation of the score from the data obtained from the questionnaire shows that the average value for the dimension is classified in the medium category. This means that the targets that have been determined enough ralistis to be achieved. However some indicators such as: Standard targets, skills, capacity, and sense of lazy relatively low. This means that the indicator is still not realistic to achieve or reach the target. While the indicators of pressure and apathy is classified as moderate, where this shows that the indicator is quite realistic.

Subsequent analysis conducted on the dimensions of "relevant". The results of the calculation of the score from the data obtained from the questionnaire shows that the average value for the dimension is classified in the low category. This means that the target specified is less or not relevant to the conditions existing in the organization, such as conformity with the objectives of the organization, with the efforts that should be done, with the expertise and suitability to the needs.

The analysis of the last of the assessment of the performance of SMART, is performed on the dimensions of "timely". The results of the calculation of the score from the data obtained from the questionnaire shows that the average value for the dimension of "timely" or the time of the assessment classified in the low category. This means that the assessment time of assessment has not yet formulated a deadline to complete the objectives that have been determined.

Based on the analysis of variables performance assessment by using SMART method, the overall variables of performance assessment is located in the medium category. This shows that the bank PT. BNI Tbk. The Main branch of Tangerang has not been able to use the SMART method, because the indicators that should be used in the method of SMART is yet to be made by the bank PT. BNI Tbk. Main Branch Tangerang.

\section{Employee Job satisfaction Bank of the BJP Center in the City of Tangerang}

The analysis of the variable employee Job Satisfaction in Banks the BJP Central starts from the dimensions of "the Work itself". The results of the calculation of the score from the data obtained from the questionnaire shows that the average value for the dimension is classified in the category of high. This suggests that the field of graphic designn feel that the work they are dealing with interesting and challenging, not boring and with such work making them have a status that is viewed. 
Subsequent analysis conducted on the dimensions of the "Wages/salary". The results of the calculation of the score from the data obtained from the questionnaire shows that the average value for the dimension is classified in the medium category. This indicates that employees feel that the system of wages or salary in the bank BNI enough mememuaskan, will tetapiuntuk amount of employees felt that the amount of salary that is received is still not satisfactory. But to the issue of timeliness of acceptance and salary component in it they feel satisfied.

Subsequent analysis conducted on the dimensions of "Promotion". The results of the calculation of the score from the data obtained from the questionnaire shows that the average value for the dimension is classified in the category of high. This indicates that employees feel that the system of promotion in the bank BNI mememuaskan, but to the rules of the promotion, they still feel not satisfied, it means that according to them there is still lack of clarity with regard to how the rules to be promoted while the line and the opportunity is open enough.

Subsequent analysis performed on the dimension "Supervision". The results of the calculation of the score from the data obtained from the questionnaire shows that the average value for the dimension is classified in the medium category. This shows that supervision is done in the bank BNI enough mememuaskan. It this happens because they consider only monitoring that is done with strict while for the control is not carried out by the supervisor. Moreover, the employee considers that the supervisor is minimal or lacking in the books direction to the employees.

Subsequent analysis is done on dimension "kelompok work." The results of the calculation of the score from the data obtained from the questionnaire shows that the average value for this dimension is classified in the medium category. This shows that the Condition of the working Groups that exist or happen in the environment of bank BNI enough mememuaskan. It happens because they consider the friendliness of fellow colleagues has not been so visible and felt, it could be due to still strong elements of seniority among employees. while for the cooperation among the fellow colleagues considered quite satisfactory by the employees.

The analysis of the last of the satisfaction of the work performed on the dimension "working Conditions/work environment." The results of the calculation of the score from the data obtained from the questionnaire shows that the average value for the dimension is classified in the category low. This shows that the working Conditions/working environment that exist or happen in the environment of the bank BNI no mememuaskan. It happens because they consider that their work place is less clean, less comfortable and has high noise so as to make comfort in the work becomes less satisfying.

Based on the analysis conducted on the variables of job satisfaction, sely the overall job satisfaction variable in the bank PT. BNI Tbk. Main branch Tangerang are in the medium category. This suggests that the bank PT. BNI Tbk. The Main branch of Tangerang can not give high satisfaction to their employees.

\section{The verification analysis}

This analysis is carried out to verify the relationship between the variables in the study. In this study it is predicted that the variable of performance appraisal has relationship with job satisfaction variables. To perform this analysis need to be described model of the relationship between the two variables as there is in figure 4 


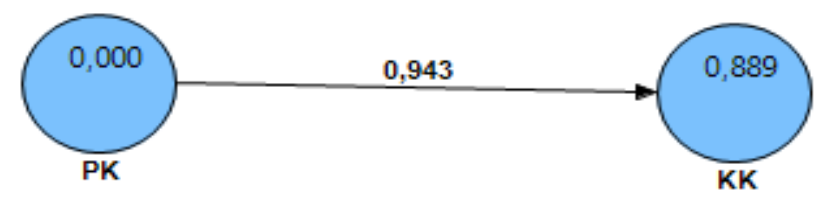

Fugure 4. Model the relationship of variables

In the picture it can be seen that $\mathrm{R}^{2}$ ( $R$ square) for the variable of job satisfaction is to 0.889 this means that this means that the variation of job satisfaction $(\mathrm{KK})$ can be explained by the construct of the assessment of the performance of SMART by $88,9 \%$ and the rest is explained by other variables. The value of $R$-square that are in the top $50 \%$ have a strong correlation.

The next stage is to perform calculations (calculate) bootstraping with the case per sample as much as 98 , the calculation result is shown as in the table below.

Table 2. The Path Coefficients (Mean, STDEV, T-Values)

\begin{tabular}{|l|c|c|c|}
\hline & $\begin{array}{c}\text { Original } \\
\text { Sample (O) }\end{array}$ & T Statistics (|O/STERR |) & $\begin{array}{c}\text { T-table } \\
(\mathbf{a}=\mathbf{5 \%})\end{array}$ \\
\hline PK -> KK & 0,942919 & 5,8737653 & 1,66 \\
\hline
\end{tabular}

In the table above, the value of the original sample (O) shows the relationship positive or negative between the variables. While the t-statistics is used to see the significance of relationship between variables. The relationship is considered significant if the $\mathrm{t}$ - statistics is greater than $\mathrm{t}$-table. With $\alpha$ of $5 \%$ obtained by $\mathrm{t}-$ by 1,66 .

\section{The influence of the Assessment of the Performance of SMART Against Kepuasan Work}

Table 2 shows that the value of the original sample $(\mathrm{O})$ of the variable Performance Appraisal $(\mathrm{KK}) \rightarrow$ Job Satisfaction (KK) by 0,9429. This means that the assessment keinerja provide a positive influence by $94.29 \%$ of job satisfaction, while the value of t-statistics is equal to 5,873, where this value is greater than the value of the t-tabel, ie 1.6 to6. The value of t-statistics greater than $t$ table-this indicates that the influence of performance appraisal on the satisfaction of employee is significant. These results indicate that the assessment of the performance of the very airinfluence positive significant toward the job satisfaction of the employee, where: if the assessment work is done well then employee satisfaction will also increase, conversely if the assessment work is not done well then the job satisfaction of employees will decrease.

The results of this study support the bed studies previously found that performance has positive relationship with job satisfaction, job satisfaction, perceived employee will encourage them to give good performance. Job satisfaction is the attitude of employees towards how they perceive their work. Job satisfaction can provide several benefits, such as creating a harmonious relationship between the company and the employee. The satisfaction or dissatisfaction of employees is the response of the employees to evaluate the level of conformity between previous expectations and the performance of the design work of actual is perceived by the employees. 
Some researchers found that job satisfaction is very dpengaruhi by peneliaian performance or job evaluation. The assessment process is correlated effectively with the level of satisfaction and engagement of employees is high (Dechev, 2010), performance appraisal system is not effective will create chaos and confusion from top to bottom as a result chances of success and the growth of the organization going down (Khan, 2008), assessment of employees to encourage performance monitoring without the consequences of monetary, have a detrimental effect on the level of job satisfaction (Kampköttert, 2014).

\section{CONCLUSION}

Assessment of the performance of employees at PT BNI Tbk. Main branch Tangerang by using the SMART method still can not be done because some of the indicators that is required in this method have not been conducted. PT BNI Tbk. The Main branch of Tangerang can not give the satisfaction of work that is optimum for its employees. Penerapan SMART method towards employee job satisfaction PT BNI Tbk. Main branch Tangerang provide a significant positive influence on employee job satisfaction.

\section{REFERENCES}

Handoko, Hani. 2001.Personnel management and Human Resources. Yogyakarta: BPFE Yogyakarta, indonesia.

Luthans, Fred. 2006. Behavior Organizational edition 10. Yogyakarta: ANDI Yogyakarta.

Mangkunegara, Anwar Prabu. 2009. Human Resource management Perusa-haan. Tangerang: PT remaja Ros Dakarya.

Robins, Stepent P. and Timoty A. Judge. 2008. The Behavior Of The Organization. Jakarta:Salemba Four.

Sutrisno, Edy. 2009. Human Resource Management. Jakarta: Kencana Prenada Media Group. http://www.kompasiana.com/rezawahyu/metode-smart-untuk-penetapan-target-dan-carameraihnya-dengan-motivasi-kerja-ikhlas_5516fef48133113b4cbc 7231.

Bhatia, Kanchan and Jain, Prashant. 2012. A study of performance appraisal and organizational effectiveness in terms of individual and organizational base. A comparative study of BSNL and AIRTEL. International Journal on Arts, Management and Humanities 1(1): 63-72 (2012)

Dechev, Zachary. 2010. Effective Performance Appraisal - a study into the relation between employer satisfaction and optimizing business results. ERASMUS UNIVERSITY ROTTERDAM Faculty of Economics of Business Department of Economics August 2010

Prasad, Parveen. 2015. PERFORMANCE APPRAISAL: An Empirical Study to understand Job Satisfaction and Motivation of personnel through the system. International Journal of Engineering and Applied Sciences (IJEAS) ISSN: 2394-3661, Volume-2, Issue-4, April 2015

Khan, Ayaz. Performance Appraisal's Relation with Productivity and Job Satisfaction. PhD Scholar, Department of Management Science, Qurtuba University of Science \& IT, D. I. Khan, Pakistan.

Kampkötter, Patrick. 2014. Performance Appraisals and Job Satisfaction. SOEP papers on Multidisciplinary Panel Data Research,University of Cologne, June 2014. 